$(60 \%)$ were non-smokers, $33(60 \%)$ had a BMI $\geq 25$, with mean (SD) baseline disease activity of ASDAS: 3.3 (1.0) and BASDAI: 5.4 (2.0). The frequency of patients achieving clinical response was higher in males than females (LDA: $74 \%$ vs $37 \% ; p=0.02$, respectively) (Table 1). After adjusting for confounders, male gender was significantly associated with higher probability of achieving LDA (ASDAS OR=4.4; $\mathrm{p}=0.03$ and BASDAI $\mathrm{OR}=6.0 ; \mathrm{p}=0.01$ ), and clinical improvement (dASDAS: $\mathrm{OR}=4.8 ; \mathrm{p}=0.04$ and BASDAI50: OR=5.19; $\mathrm{p}=0.03)$. In the group of $\mathrm{pPsA}, 20(37 \%)$ were males, $37(68 \%)$ were non-smokers, $34(63 \%)$ had a $\mathrm{BMI} \geq 25$, with mean (SD) baseline disease activity indexes of DAPSA: 26 (14.9) and DAS 28: 4.8 (1.2). The frequency of patients achieving LDA was higher in males than females ( $74 \%$ vs $39 \% ; p=0.02$, respectively). After adjusting for cofounders, male gender was independently associated with higher probability of achieving LDA by DAPSA (OR=4.0; $\mathrm{p}=0.03)$ and DAS28 $(\mathrm{OR}=2.1 ; \mathrm{p}=0.3)$. Finally, an association between male gender and clinical improvement was also observed but this was statistically significant only when using dDAS28 as the outcome: OR=2.9; $\mathrm{p}=0.1$ for DAPSA50 and $\mathrm{OR}=5.8 ; \mathrm{p}=0.02 \mathrm{dDAS} 28$.

Conclusion: Male gender is associated with a higher rate of response to biological treatment (TNFi and $\mathrm{IL}-17 \mathrm{i})$ in both predominant articular manifestations: axPsA and pPsA. This association is robust despite using the new recommended disease activity indices and cut-off points for clinical practice. Further investigations of these gender-related differences are important for a better management of PsA.

Abstract AB0736 Table 1. Response rates after 6 months of biological therapy, stratified for PsA subtype and gender.

\begin{tabular}{|c|c|c|c|c|c|c|c|}
\hline \multicolumn{4}{|c|}{$\begin{array}{c}\text { axPsA } \\
(n=55)\end{array}$} & \multicolumn{4}{|c|}{$\begin{array}{c}\text { pPsA } \\
(n=54)\end{array}$} \\
\hline & $\begin{array}{c}\text { Males } \\
(\mathrm{n}=35)\end{array}$ & $\begin{array}{c}\text { Females } \\
(\mathrm{n}=20)\end{array}$ & $\begin{array}{c}\text { p- } \\
\text { value }\end{array}$ & & $\begin{array}{c}\text { Males } \\
(\mathrm{n}=20)\end{array}$ & $\begin{array}{c}\text { Females } \\
(\mathrm{n}=34)\end{array}$ & $\begin{array}{c}\text { p- } \\
\text { value }\end{array}$ \\
\hline \multicolumn{8}{|c|}{ LDA } \\
\hline ASDAS $<2.1$ & $25(74 \%)$ & $7(37 \%)$ & 0.02 & $\begin{array}{l}\text { DAPSA } \\
\leq 14\end{array}$ & $14(74 \%)$ & $12(39 \%)$ & 0.02 \\
\hline BASDAI $<4$ & $24(72 \%)$ & $5(26 \%)$ & 0.02 & $\begin{array}{c}\text { DAS28 s } \\
3.2 \\
\end{array}$ & $13(68 \%)$ & $6(31 \%)$ & 0.09 \\
\hline \multicolumn{8}{|c|}{ Clinical Improvement } \\
\hline dASDAS $\geq 1.1$ & $20(59 \%)$ & $7(37 \%)$ & 0.15 & DAPSA50 & $10(53 \%)$ & $11(36 \%)$ & 0.25 \\
\hline BASDAI50 & $16(48 \%)$ & $3(16 \%)$ & 0.04 & $\begin{array}{l}\text { dDAS28 } \geq \\
1.2\end{array}$ & $11(57 \%)$ & $8(42 \%)$ & 0.15 \\
\hline
\end{tabular}

Disclosure of Interests: Diego Benavent: None declared, Chamaida Plasencia Speakers bureau: Pfizer, MSD, Victoria Navarro-Compán: None declared, Alejandro Villalva: None declared, Diana Peiteado: None declared, Gemma Bonilla: None declared, Elisa Fernández: None declared, Alejandro Balsa Grant/research support from: Abbvie, Pfizer, Novartis, BMS, Nordic, Sanofi, Consultant for: Abbvie, Pfizer, Novartis, BMS, Nordic, Sanofi, Sandoz, Lilly, Paid instructor for: Pfizer, Speakers bureau: Pfizer, Novartis, UCB, Nordic, Sanofi, Sandoz, Lilly

DOI: 10.1136/annrheumdis-2019-eular.3745

\section{AB0737 ACHIEVEMENT OF RAPID3 NEAR REMISSION OR LOW SEVERITY IS ASSOCIATED WITH RESIDUAL LEVELS OF ARTICULAR AND EXTRA-ARTICULAR MANIFESTATIONS OF ACTIVE PSORIATIC ARTHRITIS IN SUBJECTS TREATED WITH APREMILAST}

Martin Bergman ${ }^{1}$, M Elaine Husni ${ }^{2}$, Yusuf Yazici ${ }^{3}$, Laura C. Coates ${ }^{4}$ Sven Richter ${ }^{5}$, Michele Brunori ${ }^{5}$, Lichen Teng ${ }^{5}$, Arthur Kavanaugh ${ }^{6} .{ }^{1}$ CrozerKeystone Health System, Ridley Park, United States of America; ${ }^{2}$ Arthritis and Musculoskeletal Center, Cleveland, United States of America; ${ }^{3}$ New York University School of Medicine, New York, United States of America; ${ }^{4}$ Nuffield Department of Orthopaedics, Rheumatology and Musculoskeletal Sciences, University of Oxford, Oxford, United Kingdom; ${ }^{5}$ Celgene Corporation, Summit, United States of America; ${ }^{6}$ University of California, San Diego, School of Medicine, La Jolla, United States of America

Background: The Routine Assessment of Patient Index Data 3 (RAPID3) is an outcome measure of disease activity widely used in the USA as part of routine care ${ }^{1}$ and is entirely derived from patient self-reported measures (Health Assessment Questionnaire-Disability Index [HAQ-DI] or multidimensional HAQ [MDHAQ], Pain visual analog scale [VAS] and Patient's Assessment of Disease Activity [PtGA] VAS). However, the lack of more objective, traditional physician assessments, such as joint counts, may lead to residual active disease that will be missed.

Objectives: To examine trajectories for improvement in RAPID3 score over time and PsA manifestations not measured specifically by RAPID3 in subjects achieving RAPID3 near remission (REM) or low disease severity at Week 52 .

Methods: Pooled analyses of the phase III PALACE 1, 2 and 3 studies were performed for subjects assigned to receive APR $30 \mathrm{mg}$ twice daily (BID) at baseline (BL). Subjects with available scores on RAPID3 compo nents (HAQ-DI, Pain VAS and PtGA VAS) at Week 52 were included and grouped according to RAPID3 categories at Week 52 (near REM: $\leq 3$; low: $>3$ to $\leq 6$; moderate: $>6$ to $\leq 12$; and high: $>12$ to 30 ). Mean RAPID3 scores were assessed from BL through Week 52. Other measures of PSA disease activity were reported longitudinally by RAPID3 category at Week 52 .

Results: The analysis included 376 APR subjects, with 42 with nea REM and 42 with low severity at Week 52. Overall, mean RAPID3 tra jectories improved overtime with greater mean improvements observed for those achieving RAPID3 near REM and low disease severity by Week 52. At a mean level, subjects in moderate RAPID3 at baseline were associated with achievement of RAPID3 near REM or low disease severity by Week 52 with APR (Figure). Many subjects who achieved RAPID3 near REM or low disease severity at Week 52 showed improvements in articular and extra-articular disease activity, although not all manifestations were controlled at Week 52 (Table); mean TJC was higher than expected in subjects achieving RAPID3 targets at Week 52 and there was no association between low mean RAPID3 and mean Psoriasis Area and Severity Index (PASI) scores.

Conclusion: At a mean level, subjects in moderate RAPID3 at baseline were associated with achievement of RAPID3 near REM or low disease severity targets with APR by Week 52 . Achievement of RAPID3 targets was associated with improvement, but not necessarily control, of all articular and extra-articular manifestations. Complementing the RAPID3 measure with joint and skin assessments may help to evaluate achievement of treatment goals in clinical practice.
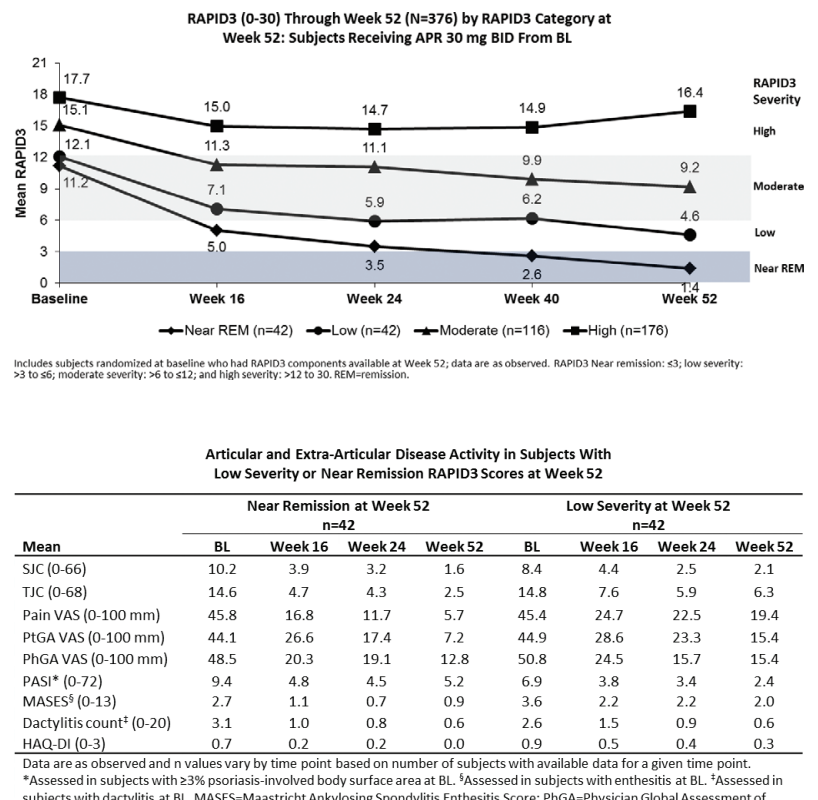

subjects with da.

\section{REFERENCES}

[1] Coates LC, et al. Arthritis Care Res. 2018;70:1198-1205.

Disclosure of Interests: Martin Bergman Shareholder of: Johnson and Johnson (parent company of Janssen), Consultant for: AbbVie, Amgen, BMS, Celgene, Genentech/Roche, Janssen, Merck, Novartis, Pfizer, and Sanofi/Regeneron, Speakers bureau: AbbVie, Amgen, BMS, Celgene, Genentech/Roche, Janssen, Merck, Novartis, Pfizer, and Sanofi/Regeneron, M Elaine Husni Grant/research support from: Janssen, Yusuf Yazici Shareholder of: Samumed, LLC, Consultant for: Celgene Corporation, BMS Genentech, Sanofi, Employee of: Samumed, LLC, Laura C Coates Grant/ research support from: AbbVie, Celgene, Lilly, Novartis and Pfizer, Consultant for: AbbVie, Amgen, BMS, Celgene, Galapagos, Gilead Sciences Inc., Janssen, Lilly, Novartis, Pfizer, Prothena Corp and UCB, Sven Richter Employee of: Celgene Corporation, Michele Brunori Employee of: 
Celgene Corporation, Lichen Teng Employee of: Celgene Corporation, Arthur Kavanaugh Grant/research support from: UCB Pharma DOI: 10.1136/annrheumdis-2019-eular.1860

\section{AB0738 DUAL NEUTRALISATION OF INTERLEUKIN (IL)-17A AND IL-17F WITH BIMEKIZUMAB IN MODERATE-TO- SEVERE PLAQUE PSORIASIS: 60-WEEK RESULTS FROM A RANDOMISED, DOUBLE-BLINDED, PHASE 2B EXTENSION STUDY}

Andrew Blauvelt ${ }^{1}$, Kim A. Papp ${ }^{2}$, Joseph F. Merola ${ }^{3}$, Alice B. Gottlieb ${ }^{4}$ Nancy Cross $^{5}$, Cynthia Madden ${ }^{5}$, Maggie Wang ${ }^{5}$, Christopher Cioffi ${ }^{6}$,Christopher E.M. Griffiths ${ }^{7} .{ }^{1}$ Oregon Medical Research Center, Portland, United States of America; ${ }^{2}$ Probity Medical Research and K Papp Clinical Research, Waterloo, Canada; ${ }^{3}$ Harvard Medical School, Brigham and Women's Hospital, Boston, United States of America; ${ }^{4}$ Icahn School of Medicine at Mount Sinai, Department of Dermatology, New York, United States of America; ${ }^{5}$ UCB Biosciences Inc., Raleigh, United States of America; ${ }^{6}$ UCB Pharma, Brussels, Belgium; ${ }^{7}$ Dermatology Centre, Salford Royal Hospital, University of Manchester, Manchester Academic Health Science Centre, Manchester, United Kingdom

Background: Psoriasis is a chronic, systemic, immune-mediated inflammatory disease associated with prominent skin manifestations. One in four patients with psoriasis also has psoriatic arthritis, ${ }^{1}$ with skin disease preceding joint manifestations in most patients. ${ }^{2}$ Interleukin (IL)-17F shares structural homology and pro-inflammatory function with IL-17A. Preclinical and early clinical data support dual neutralisation of IL-17F, together with IL-17A, as a novel targeting approach for the treatment of immune-mediated inflammatory diseases. Bimekizumab, a monoclonal antibody that potently and selectively neutralises both IL-17A and IL-17F, is in development for the treatment of psoriasis, psoriatic arthritis and ankylosing spondylitis. $^{3-5}$ In the 12-week BE ABLE 1 study (NCT02905006), bimekizumab provided rapid and substantial clinical improvements in patients with moderate-to-severe plaque psoriasis, with a safety profile consistent with previous bimekizumab studies. ${ }^{3}$

Objectives: The objectives of this Phase $2 b$ extension study (BE ABLE 2; NCT03010527) were to assess the long-term safety and efficacy of subcutaneous bimekizumab every four weeks for an additional 48 weeks (60 weeks' total exposure).

Methods: BE ABLE 1 responders $(\geq 90 \%$ reduction in Psoriasis Area Severity Index [PASI90] at Week 12) receiving placebo or bimekizumab $64 \mathrm{mg}, 160 \mathrm{mg}$, 160mg (320mg loading dose [LD]) remained on the same dose; non-responders (<PASI90 at Week 12) were re-assigned from placebo/bimekizumab $64 \mathrm{mg}$ to $160 \mathrm{mg}$ or from $160 \mathrm{mg} / 160 \mathrm{mg}$ (LD) to $320 \mathrm{mg}$ Patients previously receiving bimekizumab $320 \mathrm{mg} / 480 \mathrm{mg}$ received $320 \mathrm{mg}$ The primary variable was the exposure-adjusted incidence rate (EAIR) of treatment-emergent adverse events (TEAEs); efficacy assessments were secondary.

Results: 217 patients were enrolled. Across all doses, BE ABLE 1 responders generally maintained complete or almost complete skin clearance for up to an additional 48 weeks: PASI90: $80-100 \%$, non-responder imputation (93-100\%, observed); PASI100: $70-83 \%$ (80-96\%); Investigator's Global Assessment: $78-100 \%$ (98-100\%). PASI100 was achieved by $33-76 \%(40-82 \%)$ of non-responders (Week 48 ). EAIR of TEAEs was $206.1 / 100$ patient-years $(n=184 / 217$ [85\%]). EAIR of serious TEAEs was $6.2 / 100$ patient-years $(n=15 / 217 \quad[7 \%]) ;$ no serious TEAE was reported by $>1$ patient. The most frequent TEAEs were oral candidiasis and nasopharyngitis. No cases of suicidal ideation/behaviour, major adverse cardiac events, or inflammatory bowel disease were reported. No new safety findings were observed.

Conclusion: Nearly all BE ABLE 1 responders completing 60 weeks of bimekizumab treatment maintained complete or almost complete skin clearance, with a safety profile consistent with previous studies. ${ }^{3}$

\section{REFERENCES}

[1] Alinaghi et al. J Am Acad Dermatol 2019;80:251-65;

[2] Gladmann et al. Ann Rheum Dis 2005;64:ii14-17;

[3] Papp et al. J Am Acad Dermatol 2018;79:279-286;

[4] Van der Heijde et al. Ann Rheum Dis 2018;77:A70;

[5] Ritchlin et al. Arthritis Rheumatol 2018;70(S10):L17

Acknowledgement: The study was funded by UCB Pharma.

Disclosure of Interests: Andrew Blauvelt Grant/research support from: AbbVie, Aclaris, Akros, Allergan, Almirall, Amgen, Boehringer Ingelheim, Celgene, Dermavant, Dermira Inc, Eli Lilly and Company, Galderma,
Genentech/Roche, GlaxoSmithKline, Janssen, LEO, Meiji, Merck Sharp \& Dohme, Novartis, Pfizer, Purdue Pharma, Regeneron, Revance, Sandoz, Sanofi Genzyme, Sienna Pharmaceuticals, Sun Pharmaceuticals, UCB Pharma, Valeant, Vidac, Consultant for: AbbVie, Aclaris, Akros, Allergan, Almirall, Amgen, Boehringer Ingelheim, Celgene, Dermavant, Dermira Inc. Eli Lilly and Company, Galderma, Genentech/Roche, GlaxoSmithKline, Janssen, LEO, Meiji, Merck Sharp \& Dohme, Novartis, Pfizer, Purdue Pharma, Regeneron, Revance, Sandoz, Sanofi Genzyme, Sienna Pharmaceuticals, Sun Pharmaceuticals, UCB Pharma, Valeant, Vidac., Speakers bureau: Janssen, Regeneron, Sanofi Genzyme, Kim A. Papp Grant/ research support from: AbbVie, Akros, Allergan, Amgen, Anacor, Arcutis, Astellas, Baxalta, Boehringer Ingelheim, Bristol-Meyers Squibb, Can-Fite Biopharma, Celgene, Coherus, Dermira, Dow Pharma, Eli Lilly, Galderma, Genentech, Gilead, GlaxoSmithKline, InflaRx GmbH, Janssen, Kyowa Hakko Kirin, LEO, Medlmmune, Merck (MSD), Merck-Serono, Moberg Pharma, Novartis, Pfizer, PRCL Research, Regeneron, Roche, SanofiAventis/Genzyme, Takeda, UCB Pharma, Valeant/Bausch Health, Consultant for: AbbVie, Akros, Amgen, Arcutis, Astellas, AstraZeneca, Baxalta, Baxter, Boehringer Ingelheim, Bristol-Meyers Squibb, Can-Fite Biopharma, Celgene, Coherus, Dermira, Dow Pharma, Eli Lilly, Forward Pharma, Galderma, Genentech, Janssen, Kyowa Hakko Kirin, LEO, Meiji Seika Pharma, Merck (MSD), Merck-Serono, Mitsubishi Pharma, Novartis, Pfizer, PRCL Research, Regeneron, Roche, Sanofi-Aventis/Genzyme, Takeda UCB Pharma, Valeant/Bausch Health, Speakers bureau: AbbVie, Amgen, Astellas, Celgene, Eli Lilly, Galderma, Janssen, Kyowa Hakko Kirin, LEO, Merck (MSD), Novartis, Pfizer, Sanofi-Aventis/Genzyme, Valeant/Bausch Health, Joseph F. Merola Consultant for: Biogen IDEC, Abbvie, Amgen, Eli Lilly and Company, Novartis, Pfizer, Janssen, UCB, Samumed, Celgene, Sanofi Regeneron, Merck, and GSK, Alice B. Gottlieb Grant/ research support from: Incyte Corporation, Janssen Ortho Inc, Lilly ICOS LLC, Novartis, UCB, XBiotech, Consultant for: AbbVie, BMS, Celgene Corporation, Dermira, Incyte Corporation, Janssen Biotech, Janssen Ortho Inc, LEO Pharma, Lilly ICOS LLC, Novartis, Sun Pharmaceuticals Ltd, UCB, Speakers bureau: AbbVie, Eli Lilly and Company, Janssen Biotech, Nancy Cross Employee of: UCB Biosciences Inc, Cynthia Madden Shareholder of: UCB Biosciences Inc, Employee of: UCB Biosciences Inc, Maggie Wang Employee of: UCB Biosciences Inc, Christopher Cioff Shareholder of: UCB Biosciences Inc, Employee of: UCB Biosciences Inc, Christopher E.M. Griffiths Grant/research support from: AbbVie, Celgene, LEO, Lilly, Janssen, Novartis, Pfizer, Sandoz, UCB Pharma, Speakers bureau: AbbVie, Almirall, Bristol-Meyers Squibb, Celgene, Galderma, Janssen, Lilly, Novartis, Pfizer, Sandoz, UCB Pharma DOI: 10.1136/annrheumdis-2019-eular.4166

\section{AB0739 THE PREVALENCE OF PSYCHOLOGICAL DISORDERS IN PATIENTSWITH SEVERE PSORIASIS WITH/WITHOUT PSORIATIC ARTHRITIS IN CLINICAL PRACTICE: DATA FROM A SINGLE DERMATOLOGICAL SETTING}

Maria Chamurlieva ${ }^{1}$, Alkes Khotko ${ }^{2}$, Larisa Kruglova ${ }^{3}$, Svetlana Glukhova ${ }^{1}$, Tatiana Korotaeva ${ }^{1} .{ }^{1}$ V.A. Nasonova Research Institute of Rheumatology, Moscow, Russian Federation; ${ }^{2} \mathrm{Clinical}$ Hospital of the KKVD MH KK, Krasnodar, Russian Federation; ${ }^{3}$ Central State Medical Academy, Moscow, Russian Federation

Background: Psoriatic arthritis ( $\mathrm{PsA}$ ) and Psoriasis ( $\mathrm{PsO}$ ) are associated with different psychological disorders. Depression is a risk factor for development of PsA among PsO patients (pts). Diagnosis of PsA in dermatological practice is still problematic. The prevalence of psychological disorders in patients with severe $\mathrm{PsO}$ with/without PsA are limited in the Russian Federation.

Objectives: To study the prevalence of anxiety, depression and fatigue in pts with severe PsO with/without PsA in a single dermatological setting. Methods: 99 unselected pts (male-23/female-76) with severe plaque PsO, mean age $45.82 \pm 14.04$ years, BSA $56.35 \pm 9.11 \%$, PASI $22.50 \pm 5.13$ were included. PsA was diagnosed by the CASPAR criteria. Anxiety, depression and fatigue were identified by the Hospital Anxiety Scale (HADS-A), HADS-Depression (HADS-D) and Functional Assessment of Chronic Illness Therapy (FACIT) (points) accordingly. The HADS-A/HADS$D$ was defined as normal - 0-7; presence of disorders - 8-10; psychiatric morbidity $>11$ points accordingly. FACIT $43.6 \pm 9.4$ matched with healthy control. The lower the level of FACIT corresponded to higher fatigue. The number of pts with FACIT $\leq 30$ were calculated. All pts were treated with different synthetic DMARDs, mostly Methotrexate (subcutaneous 15$20 \mathrm{mg}$ every week), biological DMARDs according local therapy according 